\title{
In situ Observation of Carbon-Nanopillar Tubulization Caused by Liquidlike Iron Particles
}

\author{
Toshinari Ichihashi, ${ }^{1,3, *}$ Jun-ichi Fujita, ${ }^{2,3}$ Masahiko Ishida, ${ }^{1,3}$ and Yukinori Ochiai ${ }^{1,3}$ \\ ${ }^{1}$ Fundamental and Environmental Research Laboratories, NEC Corporation, 34 Miyukigaoka, Tsukuba 305-8501, Japan \\ ${ }^{2}$ Institute of Applied Physics, University of Tsukuba, 1-1-1 Tennoudai, Tsukuba 305-8573, Japan \\ ${ }^{3}$ CREST JST, Kawaguchi Center Building, 4-1-8, Hon-cho, Kawaguchi, Saitama 332-0012, Japan
}

(Received 15 January 2004; published 25 May 2004)

\begin{abstract}
The tubulization process of amorphous carbon nanopillars was observed in situ by transmission electron microscopy. Amorphous carbon nanopillars were transformed into graphitic tubules by annealing at $650-900{ }^{\circ} \mathrm{C}$ in the presence of iron nanoparticles. A molten catalyst nanoparticle penetrated an amorphous carbon nanopillar, dissolving it, and leaving a graphite track behind. An iron nanoparticle moved with its shape changing like an earthworm. We concluded that the tubulization mechanism is a solid-(quasiliquid)-solid mechanism where the carbon phase transformation is a kind of liquid phase graphitization of amorphous carbon catalyzed by liquefied metal-carbon alloy nanoparticles.
\end{abstract}

DOI: 10.1103/PhysRevLett.92.215702

PACS numbers: 64.70.Kb, 61.46.+w, 68.37.-d, 81.07.De

Carbon nanotubes [1-3] are currently the focus of intense research because of their unique properties and potential to impact broad areas of science and technology. However, despite the enormous progress in nanotube synthesis [4-6], the carbon nanotube growth mechanisms are still being searched for because there have been no direct observations of the carbon nanotube growth process. Here we report on our in situ observation of the tubulization process of amorphous carbon nanopillars by transmission electron microscopy.

Figure 1 shows our sample preparation method. First, we deposited an iron-doped amorphous carbon foundation, which was about $1 \mu \mathrm{m}$ thick, on a molybdenum grid for the transmission electron microscope (TEM) through focused-ion-beam-induced chemical vapor deposition [7] using a ferrocene $\left(\mathrm{FeC}_{10} \mathrm{H}_{10}\right)$ gas source [8] injected through a nozzle. Next, we grew amorphous carbon pillars, which were $10-100 \mathrm{~nm}$ in diameter and $100-500 \mathrm{~nm}$ long, on the iron-doped carbon foundation through electron-beam-induced chemical vapor deposition [9] in a phenanthrene $\left(\mathrm{C}_{14} \mathrm{H}_{10}\right)$ gas ambient [10]. Figure 1(c) shows a scanning electron micrograph of a prepared sample.

The molybdenum grid, on which the iron-doped carbon foundation with the amorphous carbon nanopillars was grown, was set on a heating stage of an ultrahigh-vacuum (UHV) TEM (JEOL 2000FXVII). The UHV-TEM was equipped with a video camera [11]. The graphitization process of the amorphous carbon pillars was observed in situ by UHV-TEM operated at $200 \mathrm{keV}$ and was recorded on videotape at a TV-rate time resolution.

Figure 2(A) shows a sketch of the pillar in each annealing stage. The specimen holder was heated and kept at $600{ }^{\circ} \mathrm{C}$ until the drift of the specimen holder stopped (about $2 \mathrm{~h}$ ). During this process, the electron beam intensity was decreased to about $0.1 \mathrm{~A} / \mathrm{cm}^{2}$ (about $1 / 1000$ of the high-resolution TEM observation condition) to avoid electron beam damage to the carbon nanopillars. When the temperature of the specimen reached about $600{ }^{\circ} \mathrm{C}$, iron particles about $2 \mathrm{~nm}$ in size appeared in the iron-doped carbon foundation immediately. Because of the coalescence of the particles, the size of the iron

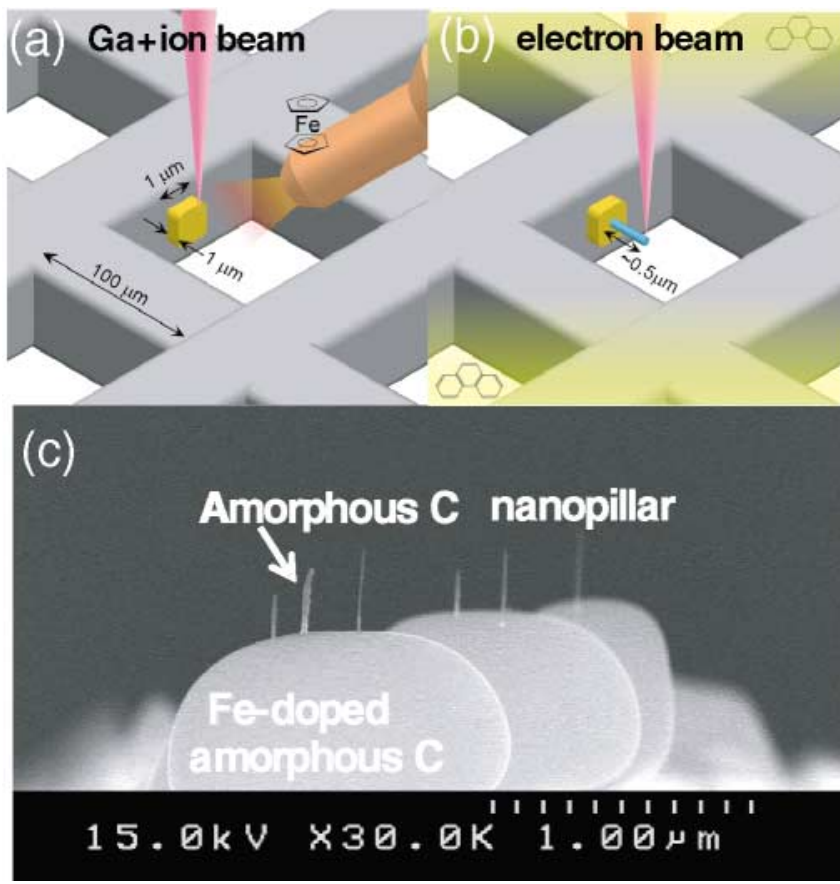

FIG. 1 (color). Schematic diagram of the sample preparation method. (a) An iron-doped amorphous carbon foundation was deposited on a molybdenum grid for the transmission electron microscope (TEM) through focused-ion-beam-induced chemical vapor deposition using a ferrocene $\left(\mathrm{FeC}_{10} \mathrm{H}_{10}\right)$ gas source injected through a nozzle. (b) Amorphous carbon pillars were grown on an iron-doped carbon foundation by electron-beaminduced chemical vapor deposition in a phenanthrene $\left(\mathrm{C}_{14} \mathrm{H}_{10}\right)$ gas ambient. (c) A scanning electron micrograph of a prepared sample. 


\section{(A)}

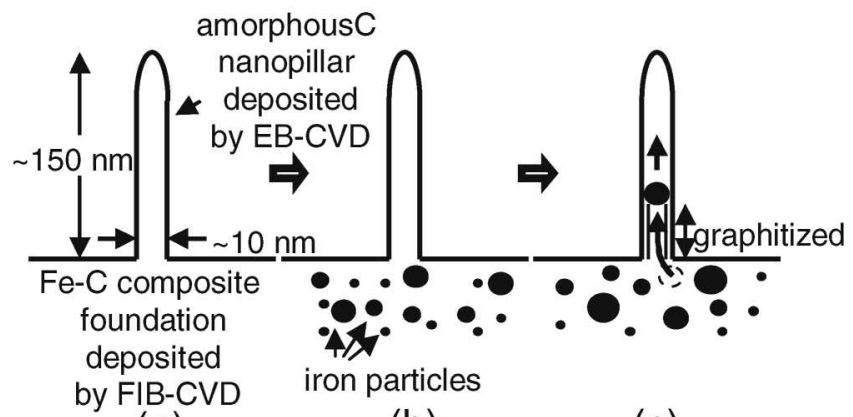

(a)

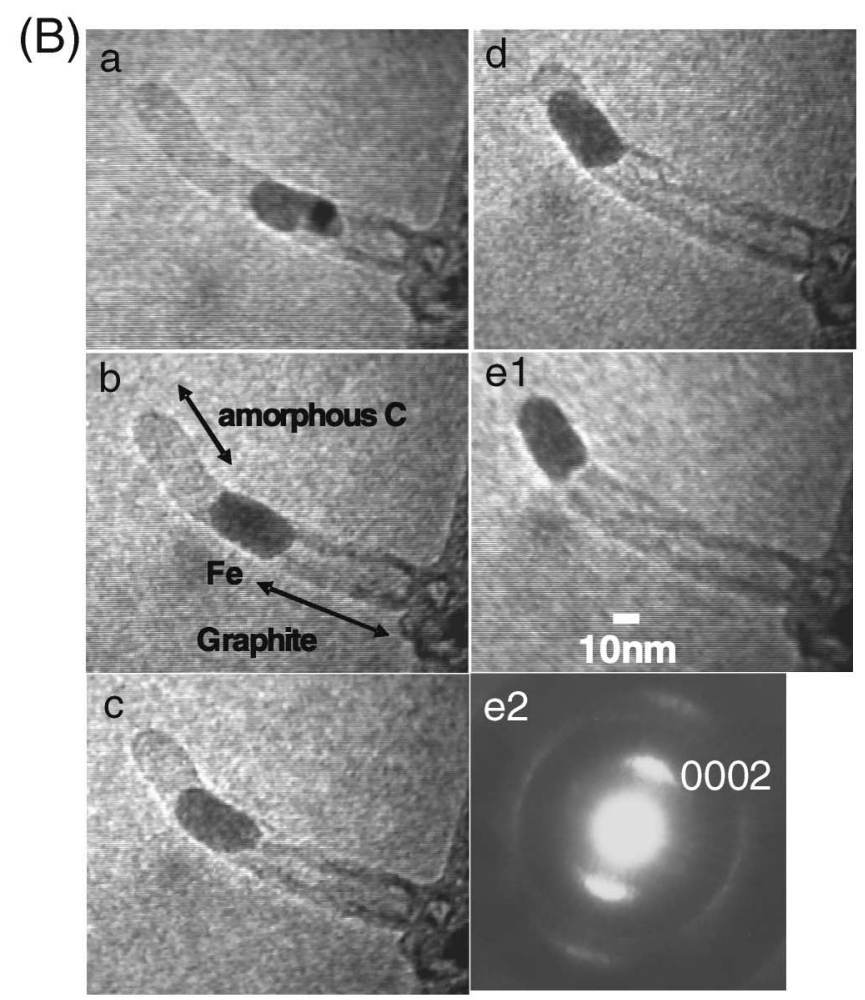

FIG. 2. (A) A sketch of the pillar in each annealing stage: (a) A prepared sample. (b) A sample was heated at $600^{\circ} \mathrm{C}$. Iron-carbon alloy particles appeared in the foundation within a few minutes. (c) A sample was heated at $650{ }^{\circ} \mathrm{C}$. An ironcarbon alloy particle was sintered into a carbon nanopillar and graphitization started from the bottom of the pillar. (B) A series of transmission electron micrographs, recorded from videotape at 2-s time intervals, showing the graphitization process of an amorphous carbon nanopillar about $10 \mathrm{~nm}$ in diameter at about $650{ }^{\circ} \mathrm{C}$. An electron diffraction pattern (e2) shows that the pillar had a graphitic structure.

particles increased to $10 \mathrm{~nm}$ in a few minutes [Fig. 2(A)(b)]. When the drift of the specimen holder stopped, the temperature of the specimen holder was raised from 600 to $650{ }^{\circ} \mathrm{C}$. Though the specimen holder again began drifting slowly, the image of the specimen could still be monitored by the UHV-TEM camera. An iron particle moved toward the bottom of a pillar and sintered into the pillar [Fig. 2(A)-(c)]. The particle changed its shape and size much like a liquid while moving in the pillar. This liquidlike particle moved through the inside of the carbon nanopillar and left behind a graphitic track.

Figure 2(B) shows a series of electron micrographs, reproduced from videotape at 2 -s time intervals, taken from a 10 -nm-diameter carbon nanopillar at about $650{ }^{\circ} \mathrm{C}$. The iron-carbon alloy particle moved from the bottom toward the top of the pillar. Once it reached the top of the pillar, the particle stopped moving. The mean speed of the iron-carbon alloy particle was about $8 \mathrm{~nm} / \mathrm{s}$. Figure 2(B)-(e2), an electron micrograph corresponding to Fig. 2(B)-(e1), shows an electron diffraction pattern taken from the carbon nanopillar. This revealed that the carbon nanopillar had a graphitic structure. The carbon nanopillar was transformed into a multiwalled (about ten layers) carbon nanotube by this heating process. However, the nanotube was not straight and contained some defects. We thought that these defects were caused by fluctuation in the moving speed of the iron-carbon alloy particle and in the particle diameter. A molten catalyst nanoparticle penetrated the amorphous carbon nanopillar, dissolving it and precipitating carbon atoms at the tail of the nanoparticle. These atoms arranged themselves into a graphene sheet. The equilibrium eutectic temperature of the corresponding iron-carbon alloy is $1150^{\circ} \mathrm{C}$. The temperature of $650^{\circ} \mathrm{C}$, at which the catalyst particles acted as a liquid in this experiment, was extremely low by comparison. It is well known that the melting points of nanometer-sized particles are much lower than those of the corresponding bulk materials [12]. Considering the size effect, the equilibrium eutectic temperature of a $10-\mathrm{nm}$-particle-size alloy is reduced to $1000^{\circ} \mathrm{C}$. On the other hand, Yudasaka et al. reported that the lowest temperature at which carbon diffuses into a 10 -nm-thick iron film and recrystallizes as graphite is about $500-600^{\circ} \mathrm{C}$ [13].

A series of electron micrographs, reproduced from videotape [14] at 1 -s time intervals, of a 10-nm-diameter carbon nanopillar at about $650^{\circ} \mathrm{C}$ is shown in Fig. 3(A). The iron-carbon alloy particle moved from the bottom toward the top of the pillar with its shape changing like a liquid. These shape changes, between the shrunken shape of the tail and elongated shape of the top, are repeated like an earthworm. When the catalyst particle moved at constant speed, the graphitic tube structure was formed. If the tail of the particle stayed at the same place for a few hundred milliseconds, the graphene sheet closed to make a cap within the nanotube (arrows 1 and 2). The precipitation interface between the graphitic tube and the catalyst particle (indicated by arrowheads) had a flat shape. TEM images of the moving catalyst particle showed sometimes diffraction contrast, which revealed that the particle had crystalline nature. The concept of the quasisolid state, which is neither solid nor liquid, has been 


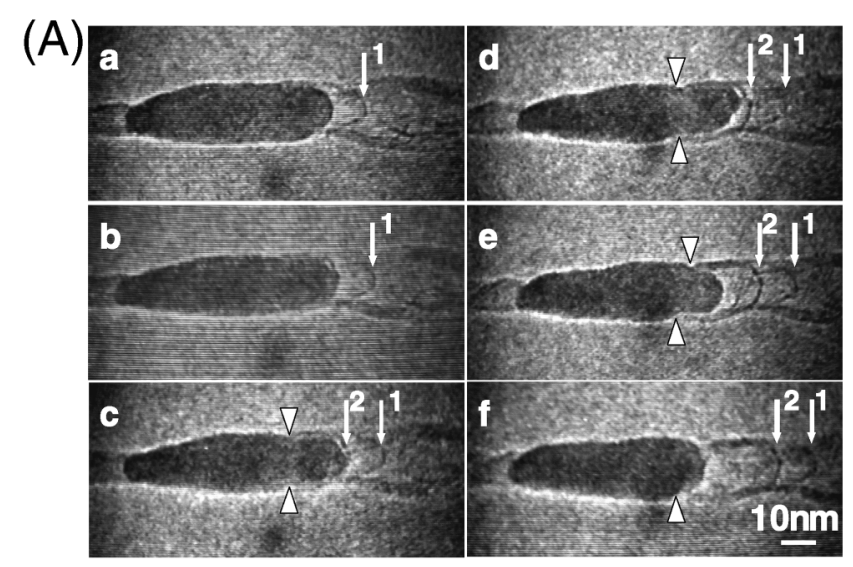

(B) (a)

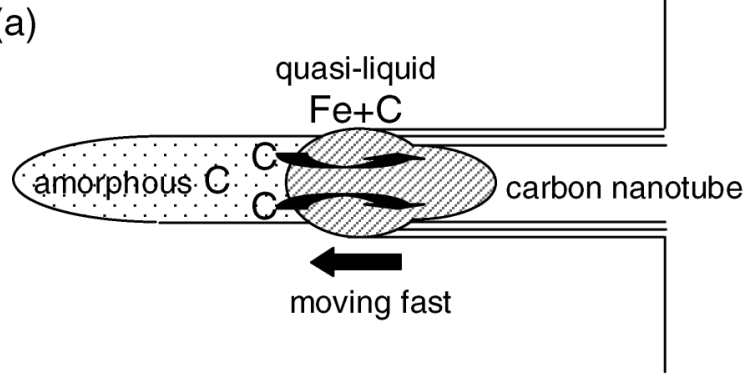

(b)

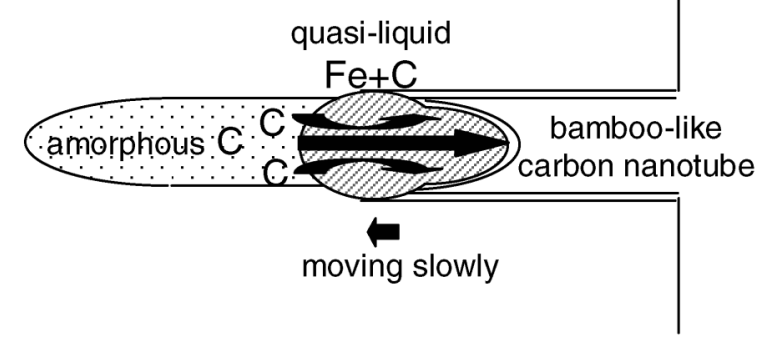

FIG. 3. (A) A series of electron micrographs, reproduced from videotape at 1 -s time intervals, taken from a $10-\mathrm{nm}-$ diameter carbon nanopillar at about $650{ }^{\circ} \mathrm{C}$, and (B) a model of the carbon nanotube growth mechanism. Arrowheads indicate the precipitation interface between the graphitic tube and catalyst particle. Arrows 1 and 2 indicate the bamboolike structure. The catalyst particle moved smoothly (a) and not smoothly (b).

proposed for nanometer-sized particles [15]. These catalyst particles are considered quasisolid particles.

Corresponding models of this carbon nanotube growth mechanism are shown in Fig. 3(B). When the penetrating speed of the catalyst particle is constant [Fig. 3(B)-(a)], precipitating carbon incorporates at the edges of the growing nanotube. When the penetrating speed of the catalyst particle is 0 for a few hundred milliseconds [Fig. 3(B)-(b)], the precipitating carbon incorporates into a graphene cap and a bamboolike structure forms [16]. Our observations suggest that carbon atoms, which are supplied from a dissolved carbon nanopillar, diffuse through the surface layer of a catalyst particle. Based on molecular dynamics simulations, Shibuta et al. proposed that a graphene sheet is formed inside the surface of a catalyst particle [17]. We thought that the motive force of the catalyst particle was caused by the difference between the solubility of amorphous carbon in iron and that of graphite carbon in iron. Another possible cause of the motive force is that there were temperature gradients in the nanopillar and nanoparticle.

In a thick pillar case (about $100 \mathrm{~nm}$ in diameter), graphitization occurred partially. The temperature was about $900{ }^{\circ} \mathrm{C}$. Figures 4(a) and 4(b) were reproduced from the videotape. The catalyst particle, about $10 \mathrm{~nm}$ in diameter, was smaller than the diameter of the pillar. A catalyst iron-carbon alloy particle, indicated by an arrowhead, moved rapidly inside the pillar in a random direction and transformed the amorphous carbon into the graphite track. The maximum speed of the catalyst particle was about $500 \mathrm{~nm} / \mathrm{s}$. The shape of the catalyst particle was changing, and the particle sometimes broke up and left small catalyst particles (indicated by arrows). The graphite track was clearly observed in Figs. 4(c) and 4(d) [enlarged image of 4(c)-(A)], which was taken at room temperature after annealing.

Our observation results indicate that the tubulization mechanism is a solid-(quasiliquid)-solid mechanism where the carbon phase transformation is a kind of liquid phase graphitization of amorphous carbon catalyzed by liquefied metal-carbon alloy nanoparticles $[18,19]$. The low-temperature liquefaction of catalyst particles causes the principal difference compared to the synthesis of carbon nanofibers, which are usually catalyzed by solid

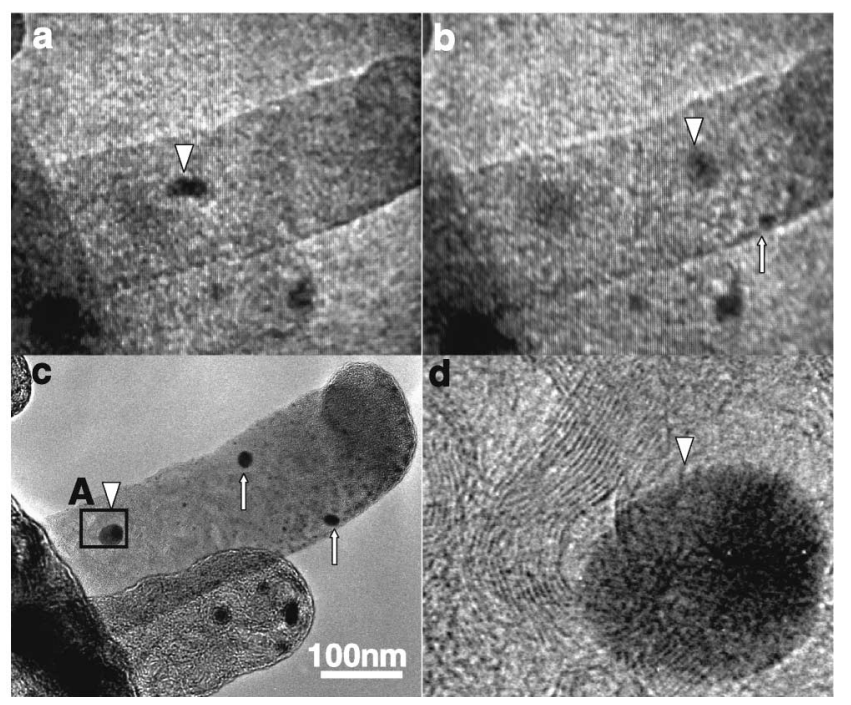

FIG. 4. A series of transmission electron micrographs showing the graphitization process of a carbon nanorod about $100 \mathrm{~nm}$ in diameter at about $900{ }^{\circ} \mathrm{C}$. (a) and (b) were reproduced from the videotape. (b) was taken $1 \mathrm{~s}$ after (a). (c) was taken at room temperature after annealing. (d) An enlarged image of the region $A$ indicated in (c). 
catalysts of similar composition in a related graphitization process.

Carbon and metal catalyst composite nanopillars can thus be fabricated at any place, in any direction, at any length, and in any thickness by using nanofabrication and heat treatment at a temperature below the equilibrium eutectic temperature of the corresponding iron-carbon alloy $\left(1150^{\circ} \mathrm{C}\right)$. Therefore, we should be able to synthesize carbon nanotubes of any desired size at any desired location.

We thank Dr. M. Yudasaka, Dr. F. Nihey, and Dr. H. Hongo for their helpful discussions.

*Electronic address: t-ichihashi@ap.jp.nec.com

[1] S. Iijima, Nature (London) 354, 56 (1991).

[2] S. Iijima and T. Ichihashi, Nature (London) 363, 603 (1993).

[3] D. S. Bethune et al., Nature (London) 363, 605 (1993).

[4] C. Journet et al., Nature (London) 388, 756 (1997).

[5] J. Kong et al., Nature (London) 395, 878 (1998).

[6] A. Thess et al., Science 273, 483 (1996).

[7] S. Matui et al., J. Vac. Sci. Technol. B 18, 3181 (2000).

[8] J. Fujita et al., J. Vac. Sci. Technol. B 20, 2686 (2002).
[9] H.W. P. Koops et al., Jpn. J. Appl. Phys. 33, 7099 (1994).

[10] J. Fujita et al., J. Vac. Sci. Technol. B 21, 2990 (2003).

[11] T. Ichihashi, Jpn. J. Appl. Phys. 35, 6610 (1996).

[12] Ph. Buffat and J-P. Borel, Phys. Rev. A 13, 2287 (1976).

[13] M. Yudasaka and R. Kikuchi, in Supercarbon in Materials Science, edited by S. Yoshimura and R. P. H. Chang (Springer-Verlag, Berlin, 1998), Vol. 33, pp. 99105.

[14] See EPAPS Document No. E-PRLTAO-92-015420 for a series of electron micrographs, reproduced from videotape. A direct link to this document may be found in the online article's HTML reference section. The document may also be reached via the EPAPS homepage (http:// www.aip.org/pubservs/epaps.html) or from ftp.aip.org in the directory /epaps/. See the EPAPS homepage for more information.

[15] S. Iijima and T. Ichihashi, Phys. Rev. Lett. 56, 616 (1986).

[16] Y. Saito and T. Yoshikawa, J. Cryst. Growth 134, 154 (1993).

[17] Y. Shibuta and S. Maruyama, Chem. Phys. Lett. 382, 381 (2003).

[18] A. Gorbunov, O. Jost, W. Pompe, and A. Graff, Carbon 40, 113 (2002).

[19] A. Gorbunov, O. Jost, W. Pompe, and A. Graff, Appl. Surf. Sci. 197-198, 563 (2002). 